\title{
MODERN CONCEPTS OF THE ANATOMY OF THE ANO-RECTAL REGION
}

\author{
By A. G. Parks, M.D., M.Ch., F.R.C.S.
}

Senior Surgical Registrar, Guy's Hospital

\section{Introduction}

It is remarkable that the anatomy of the anal canal should be still the subject of discussion. There are several reasons for this. The region is inaccessible in the cadaver because of the surrounding bony structure. Distinction between muscle fibres and connective tissue is often difficult in fixed specimens and it is easy to create artefacts by blunt dissection. Many of the complicated arrangements described in anatomical and surgical journals may well be due to excessive zeal in this respect.

The academic anatomists of the rgth century gave excellent but rather complicated descriptions; in recent years much has been written by surgeons specializing in ano-rectal disease. The articles of Milligan and Morgan (1934), Milligan, Morgan, Jones and Officer (1937) and more recently Morgan and Thompson (1956) are of special importance, as they summarize the views of surgical anatomists. There have been several excellent American contributions to this subject, those of Courtney (1950), Uhlenhuth (1953) and Gorsch (1955) being especially noteworthy.

Three methods are available for the study of anal anatomy: dissection of the cadaver, dissection during pelvic and perineal operations, and histological examination. Each has limitations and a true picture can be obtained only by integrating the knowledge obtained from all three techniques. It is still not possible to give a final account because of the complex nature of the region.

I have investigated the structure of the pelvic floor, using the thick celloidin section technique previously described (Parks, 1956), and have also studied the anatomy during the perineal dissection for excision of the rectum. A detailed account of this work will be published in the near future. The following description, which is simplified for the sake of clarity, is an attempt to synthesize the opinions of previous authors with my own observations.

\section{General Description}

'The pelvic outlet is directed almost vertically downwards and intra-abdominal pressure con $\overrightarrow{0}$ stantly exerts a force tending to drive the pelvic organs out through it. The muscles of the pelvig్ floor are arranged to prevent herniation of abdominal contents, but at the same time they mus 5 allow the egress of the alimentary and genitow urinary tracts. Most of the hiatus is closed by the two fan-shaped levator ani muscles; the only weake point is in the midline, where the viscera pas 8 through to the exterior. The muscles adjacent to the viscera are well developed in order to protece this source of weakness and are composed of striated voluntary muscle of somatic origin. $\mathrm{BE}$ their action voluntary control of the outflow of the visceral tract is established.

The anal canal is the termination of the fofie mentary viscus and possesses its own intrinsie muscle layers of smooth, involuntary muscle fibles The inner circular layer is well developed to form the internal sphincter ani and is ensheathed by the longitudinal muscle coat.

There is thus a fairly sharp division of the region into visceral and somatic components which wils form a useful basis for classification in the ensuing description (Fig. I).

\section{Embryology}

The lower rectum and upper half of the anas canal are formed from the primitive cloaca by the growth of a longitudinal septum which separates the genito-urinary tract in front from the alimentary tract behind. The muscle surrounding the cloac is modified in the course of development into the complex perineal musculature of the adult. If seems likely that the most superficial part dif o ferentiates to form the subcutaneous and super ficial parts of the external sphincter ani, the bulbow cavernosus, ischiocavernosus and superficial trans $\frac{\omega}{-}$ verse perinei muscles. The sphincter urethrae and deep external sphincter muscles develop from the deep part, most of which, howevèr, remains as $\$$ sling from the pubic arch, passing around the and canal and genito-urinary tracts, which it still treats as one. This becomes the pubo-rectalis muscle of 


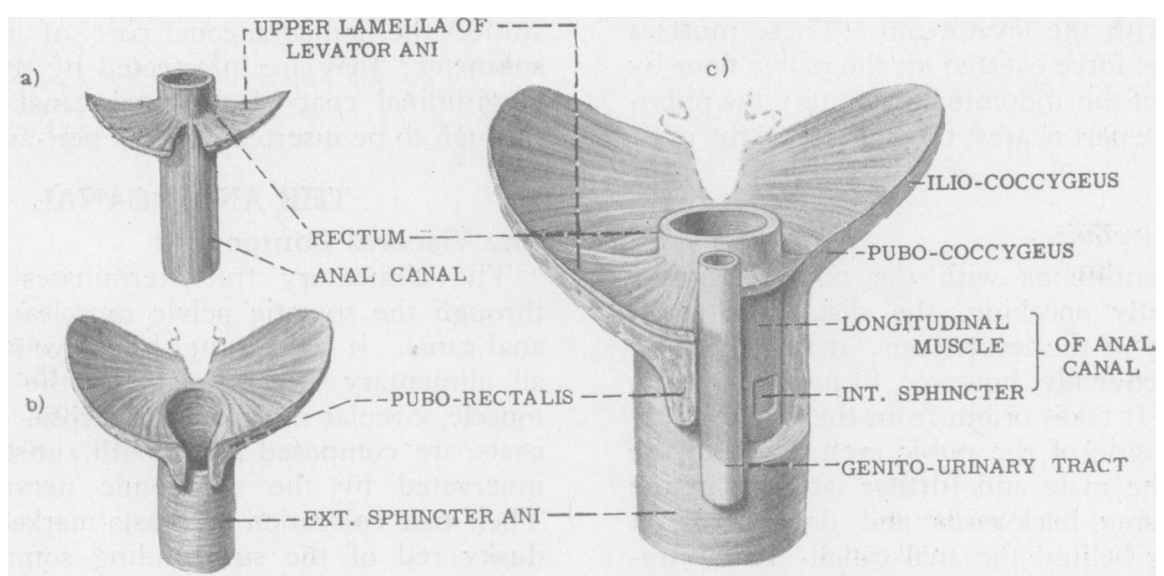

Fig. 1.-To illustrate the muscular arrangements of the pelvic floor and anal canal. (a) Shows the visceral component with attached upper lamella of the levator ani; (b) demonstrates the somatic component. Fusion of the two produces the final form as seen in (c). The genito-urinary tract is represented by the simple tube labelled 'urethra.'

adult anatomy, the most important element of the pelvic floor.

The proctodaeum and external sphincter ani are formed in response to the presence of the developing rectum; if the latter is absent, the external sphincter does not appear. The deep cloacal sphincter then encircles the vagina in the female and passes as a sling under the urethra in the male. These aberrations of development are important for the surgeon when he is attempting to create a new anal opening in cases of imperforate anus. The deep part of the cloacal sphincter is usually the only muscle capable of controlling the new anus; hence the rectum must be brought down through its arc. This entails dissecting between the muscle and the vagina in the female and between the muscle and the urethra in the male. Attempts to bring the rectum through the levator ani behind the pubic muscle sling merely result in a perineal colostomy.

\section{THE VOLUNTARY SPHINCTERS}

\section{The Somatic Component}

This group of muscles encircles the viscera as they pass through the pelvic hiatus; they form a continuous layer (Goligher et al., 1956), but may be divided into three parts for convenience of description.

\section{The Levator Ani}

The twin levatores ani muscles compose most of the pelvic diaphragm. Innervation is derived from branches of the lower sacral nerves ( $\mathrm{S}_{4}$ and ${ }_{5}$ ). Each muscle has an upper and lower lamella.

(a) The upper leaf. Striated muscle fibres arising from the pubis are inserted into the antero-lateral aspects of the longitudinal muscle coat of the rectum. The largest components are inserted close to the midline; laterally the lamella becomes tenuous. A few fibres cross in front of the rectum to join those of the opposite side (the decussating fibres of Lushka). The junction of the upper leaf of the levator ani with the longitudinal muscle forms what has been called the conjoined longitudinal muscle of the anal canal (Morgan and Thompson, 1956). The levator prevents prolapse of the anterior wall of the upper half of the anal canal and may also act as a sphincter of the urethra in the male and of the vagina in the female. During the operation of abdomino-perineal resection of the rectum it is the highest structure which must be divided anteriorly to free the rectum and allow dissection in the plane of Denonvillier's fascia.

It seems likely that muscles given such titles as ' levator prostatae' and 'deep transverse perinei' by various authors are, in fact, portions of the upper lamella of the levator. The structure designated the 'membranous diaphragm ' by anatomists is probably the connective tissue covering the lower surface of this muscle. At least part of the external sphincter urethrae in the male is formed by fibres passing under the membranous urethra. The complex arrangements of the upper layer of the levator and its associated fascial connections require further elucidation and a fresh nomenclature.

(b) The lower leaf. The muscle takes origin from a wide arc on the pelvic wall from the pubis to the spine of the ischium and is inserted into the coccyx. It is a continuous sheet, but for convenience may be divided into two parts, the pubococcygeus and ileo-coccygeus. The pelvic floor is completed by the coccygeus muscle, which is 
continuous with the levator ani. These muscles counteract the force exerted on the pelvic floor by the pressure of the abdominal contents; the pubococcygeus, the part nearest the midline, is the most powerful.

\section{The Pubo-rectalis}

This is continuous with the pubo-coccygeus and is, strictly speaking, the distal and most powerful part of the levator ani; it is sufficiently different functionally, however, to justify separate description. It takes origin from the inferior surface of each side of the pubic arch, close to the midline in the male and further laterally in the female; passing backwards and downwards, it forms a sling behind the anal canal. It has frequently been confused with the deep part of the external sphincter ani. Although the fibres do not encircle the gut completely, its most important function is that of an anal sphincter by drawing the anal canal forwards against the structures anterior to it. It forms the highest part of the 'anorectal ring' (except anteriorly), which is felt on digital palpation, and its presence gives depth to the anal canal. The pubo-rectalis is the main support of the pelvic floor and if it is weakened by prolonged stretching during childbirth, senile changes or chronic constipation the patient is liable to suffer from gynaecological or rectal prolapse. Under these circumstances the anal canal is patulous and shallow.

\section{The External Sphincter Ani}

The muscle encircles the lower half of the anal canal and is supplied by branches of the inferior haemorrhoidal nerves. Two main divisions are recognized:

(a) The deep portion is placed just below the pubo-rectalis and is continuous with it, so that the two muscles cannot be separated by dissection. It has been suggested (Courtney, 1950) that this part of the external sphincter is composed of fibres of the pubo-rectalis which cross the midline and encircle the bowel at a lower level. It is not such a powerful muscle as the pubo-rectalis.

(b) The superficial portion of the external sphincter is situated deep to the anal verge; it is part of an interlacing sheet of muscles which include the superficial transversus perinei, ischiocavernosus and bulbocavernosis. More deeply placed fibres have varying attachments from the coccyx posteriorly, the skin of the midline of the perineum and to the perineal body (so-called) anteriorly. This part of the muscle is not circular, but takes the form of an anterio-posterior ellipse, which accounts for the slit-like appearance of the anus. Immediately under the skin of the anal verge muscle fasciculi encircle the anus and con- stitute the subcutaneous part of the externap sphincter; they are intersected by strands of the? longitudinal coat of the anal canal which passin through to be inserted into the peri-anal skin.

\section{THE ANAL CANAL}

\section{The Visceral Component}

The alimentary tract terminates by passing through the somatic pelvic muscles to form the anal canal. It retains the three layers common to all alimentary viscera, namely, the longitudina muscle, circular muscle and mucosa. The muscle coats are composed of smooth, unstriped fibrešn innervated by the autonomic nervous system $\overrightarrow{0}$ Their pale coloration contrasts markedly with the dusky red of the surrounding somatic musclest when seen at operation.

\section{The Longitudinal Muscle}

The longitudinal muscle is continuous with the outer coat of the rectum and changes to connective tissue in the middle of the anal canal. It breaks up into strands near the anal margin which inter- $\omega$ sect the fasciculi of the subcutaneous part of the external sphincter. Finally, it is inserted into the skin of the anal verge. A few of the terminal fibres ${ }_{-}$ may still consist of smooth muscle, but the majoritye are collagenous interspersed with elastic fibres. Contraction of the longitudinal muscle or of a $\mathrm{ayy}$ of the muscles attached to it causes the skin $\mathbb{t o}_{0}^{\infty}$ pucker; hence the title ' corrugator cutis ani ' been given to the lowermost longitudinal fibres. Clinically, it produces a dimple around the anus, called the marginal groove. The insertion of theo longitudinal layer into the skin separates the peri- $\stackrel{\square}{\Omega}$ anal space from the ischio-rectal fossa (Fig. 2).

The longitudinal layer has numerous connective 3 tissue attachments to the surrounding somatic muscles; in this way the visceral component is welded into the voluntary sphincters. This is discussed in detail below.

\section{The Internal Sphincter}

The circular muscle is more bulky and powerfulô than in the rest of the bowel and forms the internal sphincter. There is no sharp upper line of demarcation of the sphincter; it merges imperceptibly $>$ into the circular muscle of the rectum. It is divided를. into numerous bundles separated by connectiven tissue and anastomatic vascular channels which connect the superior haemorrhoidal and pudendalo vessels. The lowermost fasciculi may reach thew anal verge, but this relationship is variable because the anal canal is so mobile that it can be invertedo or everted at will. The distal part of the internalo sphincter may be subcutaneous in eversion and an inch or more from the anal verge on inversion. $\frac{T}{0}$ It is important that the surgeon be aware of the

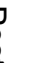




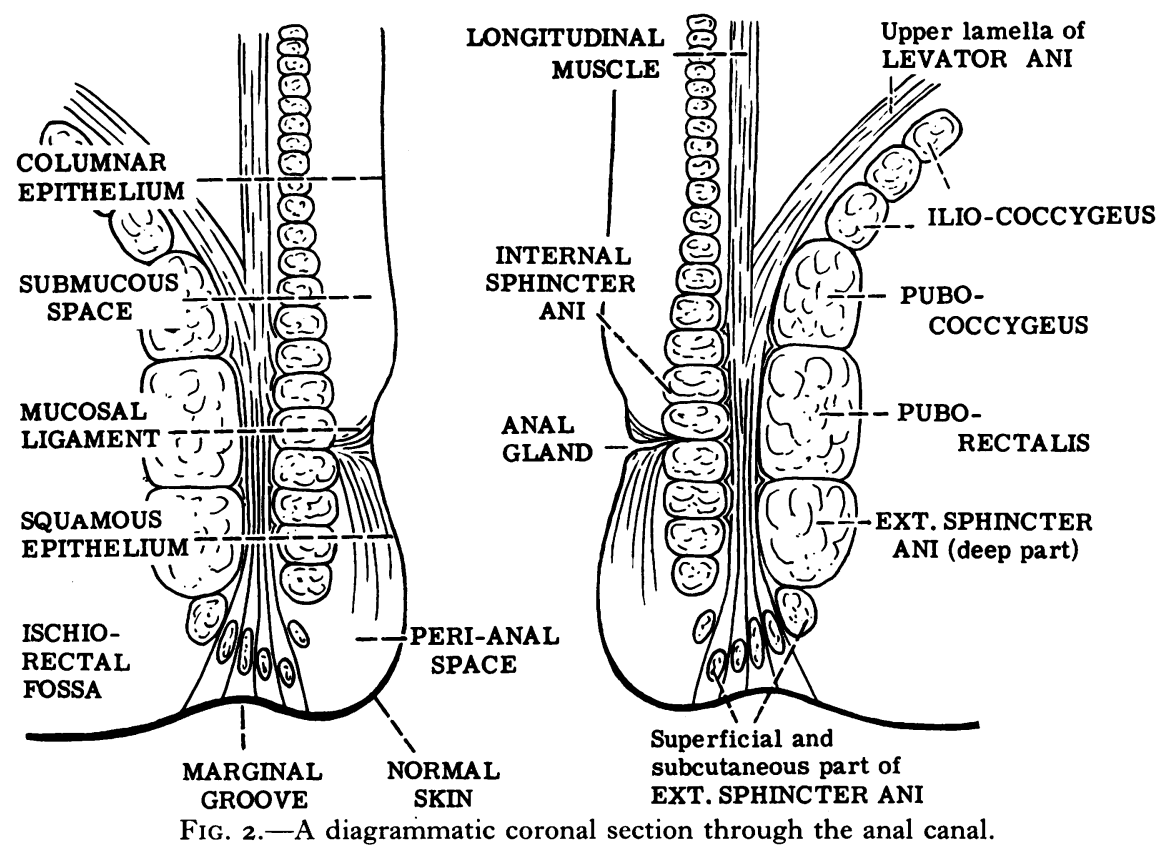

distortion which can be induced by traction on the anal skin.

The internal sphincter, being smooth muscle, is not under voluntary control; it maintains a constant tone which is a minor factor in preserving anal continence. The muscle relaxes in response to distension of the gut proximal to it, allowing evacuation to take place. Intense spasm may be caused by an anal fissure and the increased muscle tone will not subside then in response to the normal stimulus from the gut above.

\section{The Epithelium}

The upper half of the anal canal is lined by columnar epithelium identical with that of the rectum. Full thickness skin at the anal margin gradually changes to a thin layer of stratified squamous epithelium at the middle of the canal where cutaneous and visceral mucosae meet. There are several interesting features of this junctional region. The change from squamous to columnar mucosal layers may be abrupt, but usually there is a transitional region about $\frac{1}{4}$ in. in breadth of stratified mucus-secreting columnar epithelium. The highest level of the stratified zone has an undulating margin known as the pectinate or dentate line; squamous metaplasia of the columnar epithelium caused by chronic haemorrhoidal prolapse may result in this line being higher than usual. The stratified epithelium of the anal canal is derived from the skin and has a rich somatic innervation from the haemorrhoidal nerves; the lower half of the canal is therefore very sensitive.
Above the dentate line visceral innervation imparts a low degree of sensitivity to the mucosa.

The terminology of the epithelial lining of the anal canal is unsatisfactory at the present time. The transition between columnar epithelium and stratified squamous epithelium is usually referred to as the muco-cutaneous junction, which is the meaning attributed to it in this paper. However, this is not the junction of true skin and columnar epithelium because there is a broad zone of stratified squamous mucosa (similar to that of the lip) between them. Hilton's ' white line,' described in his well-known treatise, has been sought in vain by many workers (Ewing, I954); the term is confusing and should be avoided.

A circle of punctate pits, the anal crypts, is found at the muco-cutaneous junction; each has a lower crescentic border known as an anal valve. Anal glands open into the deepest parts of the crypts; they are probably rudiments of scent glands of lower mammals and are racemose in type. Their branches ramify in the submucosa of the anal canal and commonly penetrate the internal sphincter, ending blindly between it and the longitudinal muscle. Hermann and Desfosses first described them in 1880 and suggested they were the cause of peri-anal suppuration and fistula-inano. Micro-organisms seldom penetrate the alimentary wall unless an abnormality such as a perforating ulcer or infected diverticulum is present. Though this is a subject about which there is still controversy, it is the writer's opinion that the anal glands provide the only likely path- 


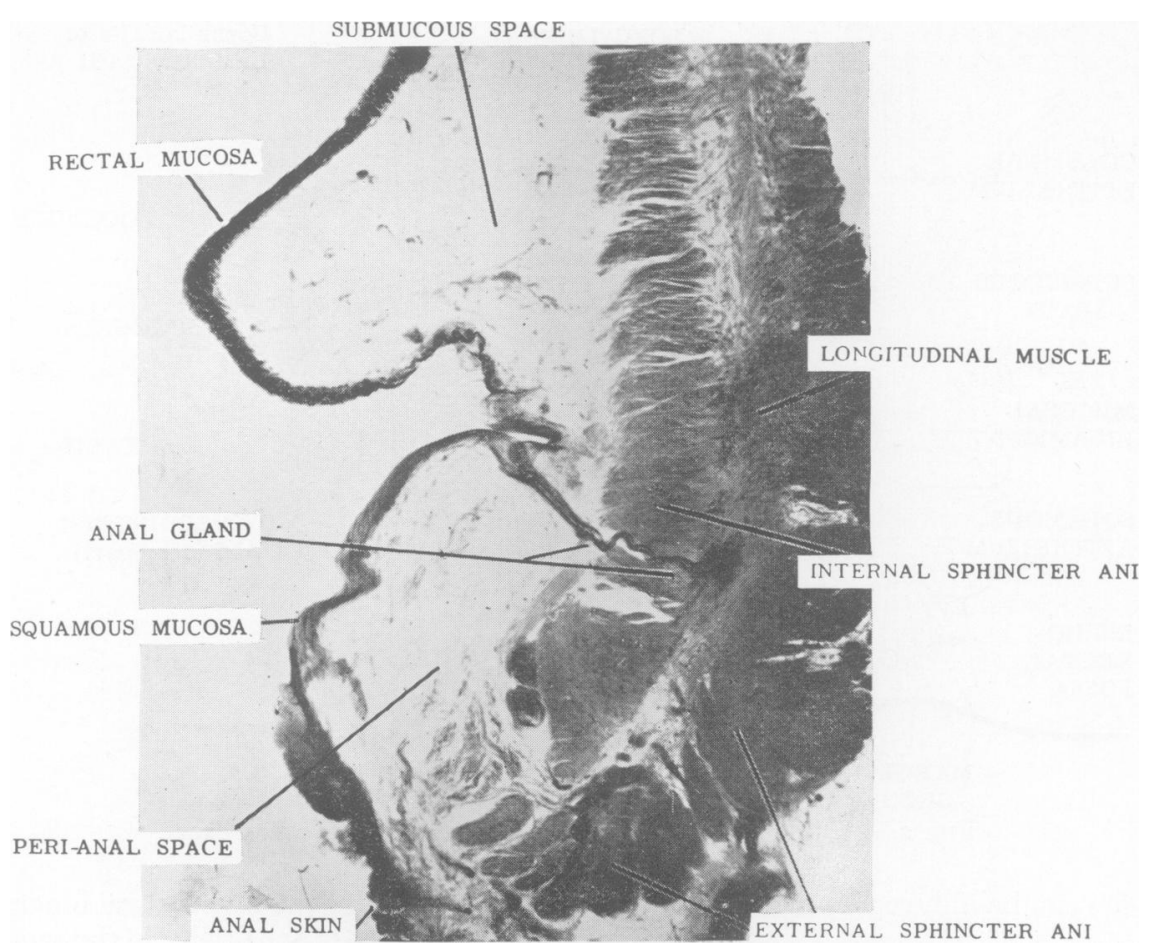

Fig. 3.-Celloidin section through the anal canal cut at $500 \mu$ to show an anal gland penetrating the internal sphincter.

way for infection to cross the internal sphincter. Pus can then track downwards between the two visceral muscles to the anal verge or through the longitudinal muscle into the fascial planes of the external sphincter and so into the ischio-rectal fossa.

Fissure-in-ano is an ulcer in the mucosa of the lower half of the anal canal; the acute variety is shallow and its base is composed of connective tissue fibres of the peri-anal space which run longitudinally. If the ulceration deepens to involve the internal sphincter, the fissure becomes chronic in type and heals very slowly. It is possible that infection in the anal glands accounts for the indolent nature of this type.

\section{The Connective Tissue of the Anal Region}

The various parts of the anal mechanism are fused into one functional unit by connective tissue. But for this, any of the three layers of the visceral component would prolapse through the anal hiatus.

All muscles have a fascial sheath and interfascicular connective tissue. It has been suggested that the longitudinal muscle sends penetrating strands into the somatic sphincters, because fibrous tissue can be traced from the longitudinal layer into the surrounding muscles in histological sections. It is more probable, however, that these strands are the intermuscular fascial sheaths wher are merely attached to the longitudinal coat. Thes attachments are attenuated in cases of rectal proळ lapse and then the visceral and somatic component\$ can be separated easily by dissection, suggesting that sliding occurs in the plane between them 3 This may also be the explanation of the ' conical anus ' described by Morgan and Thompson (1956)?

The two muscle coats are only loosely adherents in most parts of the alimentary tract; in the ana $\mathrm{B}$. canal, however, the longitudinal layer is firml attached to the fibrous stroma which surrounds and intersects the internal sphincter. The epithelium? is also attached to the connective tissue of the internal sphincter to prevent mucosal prolapse $\$$ this occurs chiefly in the middle of the anal canals the region of the anal crypts. Known as the mucosal ligament, it is especially interesting because it is concentrated around the anal glands. It forms an interrupted circle of ligamentous strands composed of collagen and smooth muscles fibres. It has been suggested (Morgan and Thompo son, $195^{6}$ ) that the mucosal ligament is formed by fibres of the longitudinal muscle layer which penetrates the internal sphincter and pass to the muco-cutaneous junction. The writer does not believe this to be the case; the appearance of con $\frac{O}{\mathbb{Q}}$ 


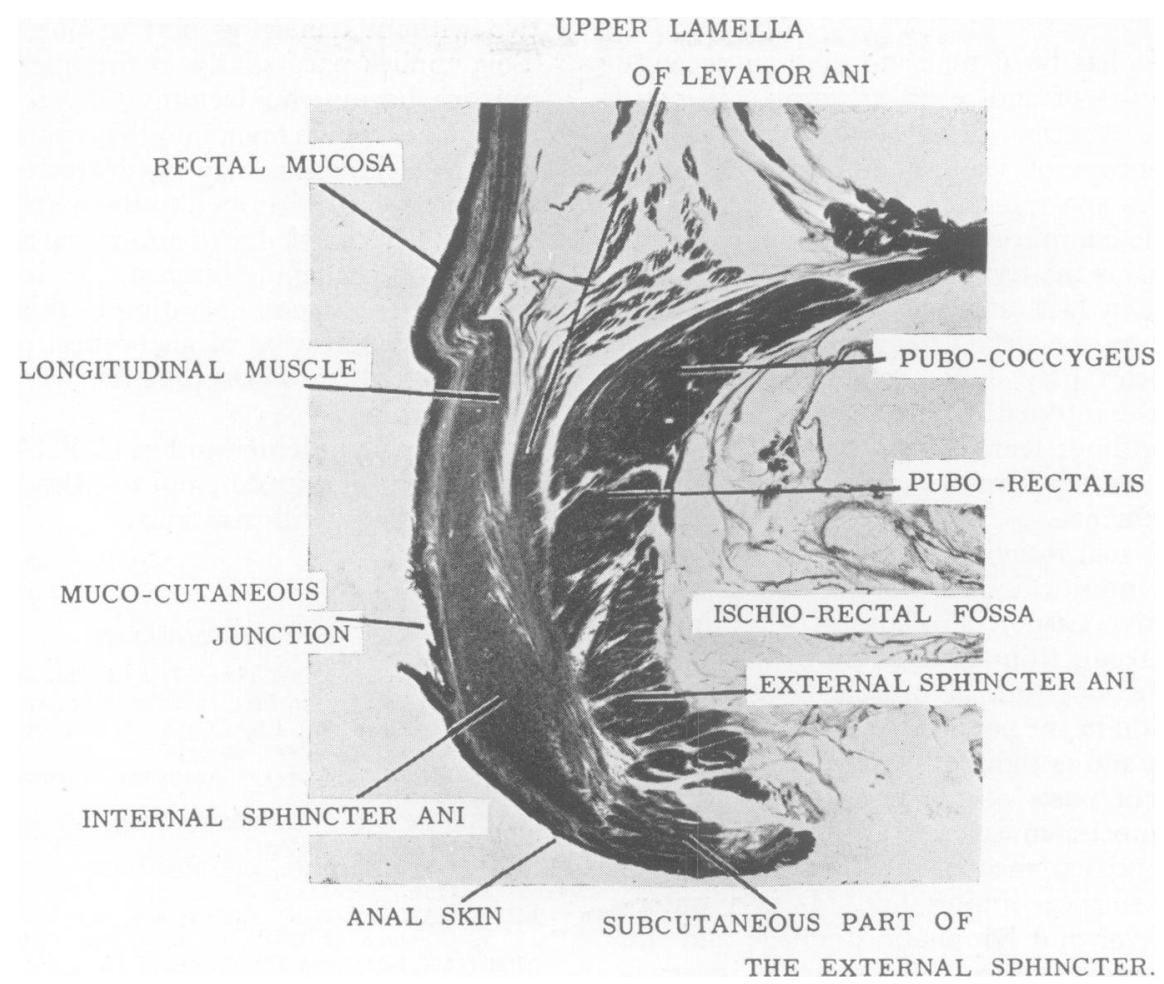

FIG. 4.-A coronal section through the pelvic floor and anal canal. Thick section cut at $200 \mu$.

tinuous fibres passing from the longitudinal layer through the internal sphincter into the submucosa is due more probably to the interlacing of connective tissue at this point.

\section{The Submucosa}

The mucosal ligament divides the space between the epithelium and internal sphincter into two parts. The submucous space containing the termination of the superior haemorrhoidal vessels is situated above the ligament; the peri-anal space is below it. Internal haemorrhoids are dilated terminal branches of the superior haemorrhoidal vein in the submucous space. The mucosal ligament is attenuated by repeated haemorrhoidal prolapse; if it disappears altogether, the mucosa is free to descend with any rise in intra-abdominal pressure and will not return spontaneously into the anal canal (a third degree haemorrhoid).

The peri-anal space extends around the lower half of the anal canal and the anal verge. The termination of the longitudinal muscle limits it circumferentially and separates it from the ischiorectal fossa. It contains blood vessels, connective tissue and branches of the anal glands. Distension of the space causes considerable pain because it is liberally innervated by the inferior haemorrhoidal nerve; for this reason peri-anal haematomata and abscesses are both painful conditions.

\section{The Para-visceral Spaces}

The submucus and peri-anal spaces are part of the visceral component, though the lower of the two is covered by cutaneous epithelium which has migrated into the lower half of the anal canal. There are several other spaces in the tissues surrounding the gut. The most important is the ischio-rectal fossa bounded medially by the levator ani, the anal sphincters and, at its lowest part, the termination of the longitudinal muscle (separating it from the peri-anal space). The lateral wall is formed by the internal surface of the ischium and muscles attached to it. The fossae on either side communicate posteriorly through the space between the anal canal and the coccyx. Perineal skin forms the floor of the fossa.

There is a para-rectal space above the levatores ani which contains fat and blood vessels. An abscess in this space may break through the levator muscles and burst in the perineum; if drainage is incomplete a ano-rectal fistula may form. 


\section{Discussion}

An attempt has been made to give an account of the principles of ano-rectal anatomy. In conclusion, three aspects will be emphasized:

I. The concept of visceral and somatic components in the ano-rectal mechanism is a help in visualizing the complicated anatomy of the region. The anal canal is the termination of the alimentary viscus; it is, in fact, a tube the lumen of which is controlled by the pelvic floor sphincters. The visceral muscles play only a small part in anal control and the internal sphincter may be divided completely without fear of loss of bowel control. Total section of the somatic sphincters, however, causes incontinence.

2. Normal anal function would not be possible without the interlocking of the various elements with connective tissue. Prolapse of one kind or another will result from attenuation of the fibrous stroma. The longitudinal muscle layer holds a central position in the connective tissue framework of the region and is indirectly attached to most of the constituent parts of the anal canal and surrounding sphincter muscles.

3. The muco-cutaneous junction is of great interest and surgical importance. It is a watershed of vascular and lymphatic drainage and the boundary between visceral and somatic innervation. The attachment of the epithelial layer to the internal sphincter at this level is important for the surgeon who may find difficulty in separating the two without damaging part of one or the others This applies particularly to the operation of subo mucous haemorrhoidectomy (Parks, 1956). The anal glands which open into the crypts at the muco cutaneous junction may have greater significance than is generally ascribed to them at present.

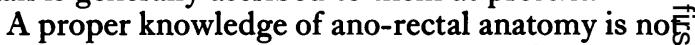
merely of academic interest; it is of immense value to the surgeon operating in this region. The technical application of anatomical principles wiles. help to reduce post-operative discomfort an morbidity.

I am much indebted to Dr. C. P. Wendell Smitk for his helpful criticism and to Miss Sylvia Tread $\overrightarrow{0}$ gold for the line illustrations.

\section{BIBLIOGRAPHY}

COURTNEY, H. (1950), Amer. F. Surg., 79, 155. EWING, M. R. (1954), Proc. roy. Soc. Med., 47, 525.

政 (1955), Brit. F. Surg., 43, 51. GORSCH, R. V. (I955), 'Proctologic Anatomy,' Williams ang Wilkins, Baltimore.

HERRMANN, G., and DESFOSSES, L. (1880), Comptes rendo Acad. des Sci., 90, 131 . MILLIGAN, E. T. C., and MORGAN, C. N. (1934), Lancet,
ii, II50.

MILLIGAN, E. T. C., MORGAN, C. N. (1934), JONES孚
L. E., and OFFICER, R. (1937), Lancet, ii, I119. MORGAN, N. C., and THOMPSON, H. R. (1956), Ann. roy. Coll
Surg. Engl., i9, 88.

PARKS, A. G. (1955), Brit. F. Surg., 43, 337.

PARKS, A. G. (1956), Ibid., 44, 209.

UHLENHUTH, E. (1953) 'Problems in the Anatomy of Pelvis,' Lippincott, Philadelphia.

\section{CARDIAC DISEASE}

\section{Price 3s. 11d. post free}

\section{INTRODUCTION}

Walter Somerville, M.D., M.R.C.P.

ANGIOGRAPHY

J. Norman Pattinson, M.B., B.Chir., D.M.R.D., F.F.R.

BEDSIDE DIAGNOSIS OF CONGENITAL HEART DISEASE

Walter Somerville, M.D., M.R.C.P.

SURGICAL TREATMENT OF CONGENITAL HEART DISEASE

W. P. Cleland, M.R.C.P., F.R.C.S.

PREGNANCY AND RHEUMATIC HEART DISEASE

Samuel Oram, M.D., F.R.C.P.
DRUG TREATMENT OF HYPERTENSION

E. G. McQueen, M.B., M.R.C.P., and F. H. Smirk, M.D., F.R.C.P.

TREATMENT OF BACTERIAL ENDOCARDITIS

Ian G. W. Hill, C.B.E., T.D., M.B., F.R.C.P.E., M.R.C.P., F.R.S.E.

THE MANAGEMENT OF COR PULMONALE J. F. Goodwin, M.D., M.R.C.P.

THE CARDIAC RISK IN ANAESTHESIA AND SURGERY

Graham W. Hayward, M.D., F.R.C.P.

Published by

THE FELLOWSHIP OF POSTGRADUATE MEDICINE

60, Portland Place, London, W.1 